\title{
Bilateral repetitive transcranial magnetic stimulation for treatment-resistant depression: a systematic review and meta-analysis of randomized controlled trials
}

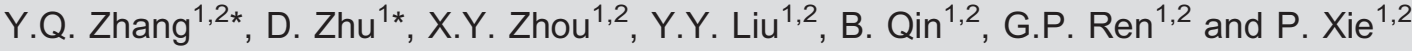 \\ ${ }^{1}$ Department of Neurology, The First Affiliated Hospital of Chongqing Medical University, Chongqing, China \\ ${ }^{2}$ Chongqing Key Laboratory of Neurobiology, Chongqing Medical University, Chongqing, China
}

\begin{abstract}
There has been concern regarding the use of controversial paradigms for repetitive transcranial magnetic stimulation (rTMS) to manage treatment-resistant depression (TRD). This meta-analysis assessed the efficacy of bilateral rTMS compared with unilateral and sham rTMS in patients with TRD. PubMed, Embase, CENTRAL, PsycINFO, Web of Science, EAGLE and NTIS databases were searched to identify relevant studies, and randomized controlled trials (RCTs) on bilateral rTMS for TRD patients were included. The response was defined as the primary outcome, and remission was the secondary outcome. Ten RCTs that included 634 patients met the eligibility criteria. The risk ratio (RRs) of both the primary and secondary outcomes of bilateral rTMS showed non-significant increases compared to unilateral $r T M S(R R=1.01, P=0.93$; odds ratio $[O R]=0.77$, $P=0.22)$. Notably, the RR of the primary bilateral rTMS outcome was significantly increased compared to that for sham $r T M S$ $(R R=3.43, P=0.0004)$. The results of our analysis demonstrated that bilateral rTMS was significantly more effective than sham rTMS but not unilateral rTMS in patients with TRD. Thus, bilateral rTMS may not be a useful paradigm for patients with TRD.
\end{abstract}

Key words: Repetitive transcranial magnetic stimulation; Treatment-resistant depression; Meta-analysis, Randomized controlled trials

\section{Introduction}

Major depressive disorder (MDD) is one of the most prevalent psychiatric disorders and contributes to significant individual suffering, disability, and increased suicide rates, as well as adverse socioeconomic effects (1). According to the World Health Organization (WHO), MDD is the third leading cause of disability worldwide, and by 2030 will become the leading cause of disease burden overall (2). Although there are several treatment approaches for MDD, an estimated $30-50 \%$ of these patients fail to benefit adequately from currently standard initial therapies, and these individuals are considered as having treatment-resistant depression (TRD) $(3,4)$. Unfortunately, TRD tends to be chronic, further exacerbating associated severe economic burdens and suicide risk (5).
In the last 20 years, a noninvasive brain stimulation technique termed repetitive transcranial magnetic stimulation (rTMS) has been developed as a clinical tool to treat depression (6). Several previous meta-analyses have demonstrated the antidepressant efficacy of high-frequency rTMS $(5-20 \mathrm{~Hz})$ applied to the left dorsolateral prefrontal cortex (DLPFC) (7-9). Low-frequency rTMS ( $\leq 1 \mathrm{~Hz}$ ) applied to the right DLPFC has also been shown to have significant antidepressant efficacy $(9,10)$. Moreover, some imaging studies have revealed an imbalance in left-right DLPFC activities in patients with MDD, with the left and right DLPFCs exhibiting lower and higher activities, respectively (11-13). Accordingly, low- and high-frequency stimulation are proposed to have opposing modulatory effects $(14,15)$.

Correspondence: Peng Xie: <xiepeng973@126.com>.

${ }^{*}$ These authors contributed equally to this study.

Received July 27, 2014. Accepted September 9, 2014. First published online January 13, 2015. 
Although rTMS has been proposed to exert an antidepressant effect by normalizing dysregulated cortical activity, the optimal treatment paradigm and parameters (e.g., placement, frequency, intensity, duration, and total stimuli) required to achieve this effect remain uncertain (16).

Although some evidence supports the use of a novel bilateral rTMS paradigm in TRD patients, the results have been conflicting $(17,18)$. A previous systematic review was performed, but its evidence was not very robust (19). We have previously investigated the diagnosis, prevention, and management of MDD (20) and are participating in a prospective randomized controlled trial (RCT) comparing the effectiveness of unilateral rTMS versus olanzapine in TRD patients. Therefore, there is an urgent need for an additional systematic review to assist clinicians in developing an optimal rTMS paradigm for patients with TRD.

\section{Research Design and Methods}

\section{Search strategy and selection criteria}

Relevant international databases (PubMed, Embase, Cochrane Central Register of Controlled Trials [CENTRAL], PsycINFO, and Web of Science) and two gray databases (European Association for Grey Literature Exploitation [EAGLE] and National Technical Information Service [NTIS]) were searched up to April 2012 (updated on January 2014) for RCTs using different combinations of the following key words: "depressive" or "depression," and "transcranial magnetic stimulation" or "TMS" or "rTMS," and "bilateral" or "combine" or "left and right prefrontal cortex" or "high and low frequency," and "resistan*" or "recurren*" or "refractory" or "non-response" or "nonresponse" or "partial response" or "incomplete response" or "failed to respond" or "treatment failure" or "inadequate response" or "insufficient response" or "persist" or "chronic." Additional relevant articles were obtained by scanning conference summaries and the reference lists of articles identified in the initial searches, and the authors of relevant RCTs were contacted to obtain additional information. No language restriction was imposed. The study protocol is available online (http://www. pengxielab.com/uploads/soft/Bilateral-rTMS-for-TRD.pdf).

The inclusion criteria were as follows: 1) a diagnosis of adult MDD based on the Diagnostic and Statistical Manual of Mental Disorders (DSM-IV, DSM-III or DSM-III-R), or the International Classification of Diseases (ICD-9 or ICD-10) criteria, 2) patients met the TRD criteria as defined by failure to respond to at least one course of adequate treatment for MDD during the current illness episode (21), and 3) RCTs that compared bilateral rTMS with other rTMS paradigms (unilateral or sham).

TRD patients with comorbid neurological disorders and psychotic disorders or specific types of depression (e.g., child and adolescent depression or postpartum depression) were excluded, as these patients often exhibit significant clinical heterogeneity in response to TRD treatment.

The literature quality was assessed using the modified
Jadad scale: 1) random sequence generation (Yes $=2$, Unclear $=1$, and $\mathrm{No}=0$ ), 2) allocation concealment (Yes = 2, Unclear $=1$, and No=0), 3) blinding of outcome assessment $(\mathrm{Yes}=2$, Unclear $=1$, and $\mathrm{No}=0)$, and 4) incomplete outcome data reported ( $\mathrm{Yes}=1$ and $\mathrm{No}=0$ ). We considered studies with total scores of $\leq 3,4$ to 5 , and $\geq 6$ as low, moderate, and high quality, respectively.

\section{Data extraction}

Two review authors (X.Y.Z. and Y.Q.Z.) independently determined whether studies met the inclusion and exclusion criteria, assessed the quality of the articles, and completed a standardized data extraction form. Any disagreements were resolved by discussion until a consensus was reached.

We used the change in depression rating scale scores at the end of treatment as the primary outcome, and the attainment of remission at the end of treatment as the secondary outcome (22). In this review, clinical response was defined as a significant improvement on certain depression rating scales (23). The cut-off points of response were $\geq 50 \%$ from the baseline score to the end of treatment score on the Hamilton Depression Rating Scale (HDRS) or the Montgomery and Åsberg Depression Rating Scale (MADRS), or "much improved" or "very much improved" on the Clinical Global Impression (CGI) scale (24). On the other hand, clinical remission was defined as a depression rating scale score within the normal range at the end of treatment (23). The remission cut-off points were a score $\leq 8$ on the 21-item HDRS, $\leq 7$ on the 17-item HDRS, a MADRS score $\leq 12$ or less, or a global rating of "not depressed" or "equivalent" on the CGI scale (24). If more than one scale was used to evaluate the response or remission within one study, HDRS was preferentially selected as the assessment scale, followed by the MADRS and CGI scales.

\section{Statistical analysis}

The overall risk ratio $(\mathrm{RR})$ was used as the effect parameter for the meta-analysis, and a 95\% confidence interval (Cl) was used to interpret the results. Heterogeneity was assessed using the chi-squared test and I-squared index $\left(I^{2}\right)$. A P value $\leq 0.1$ was deemed statistically significant, and $P^{2}$ values of 25,50 , and $75 \%$ represented low, moderate, and high heterogeneity, respectively (25). A fixed-effects model was used to analyze the pooled data with low heterogeneity. For moderate or high heterogeneity, a random-effects model was used to analyze the pooled data (26). Considering the possibility that efficacy may differ depending on the different rTMS paradigms used, we conducted subgroup analyses according to the other types of rTMS paradigm assessed. To compare the bilateral and unilateral rTMS groups, subgroup analyses were conducted based on bilateral rTMS parameters (e.g., stimulation pattern, frequency, intensity, duration, and total stimuli). Inverted funnel plots and a regression test were used to assess publication bias (26). The study was conducted by following the protocol of the meta-analysis available online as cited above. The Statistical Analysis 


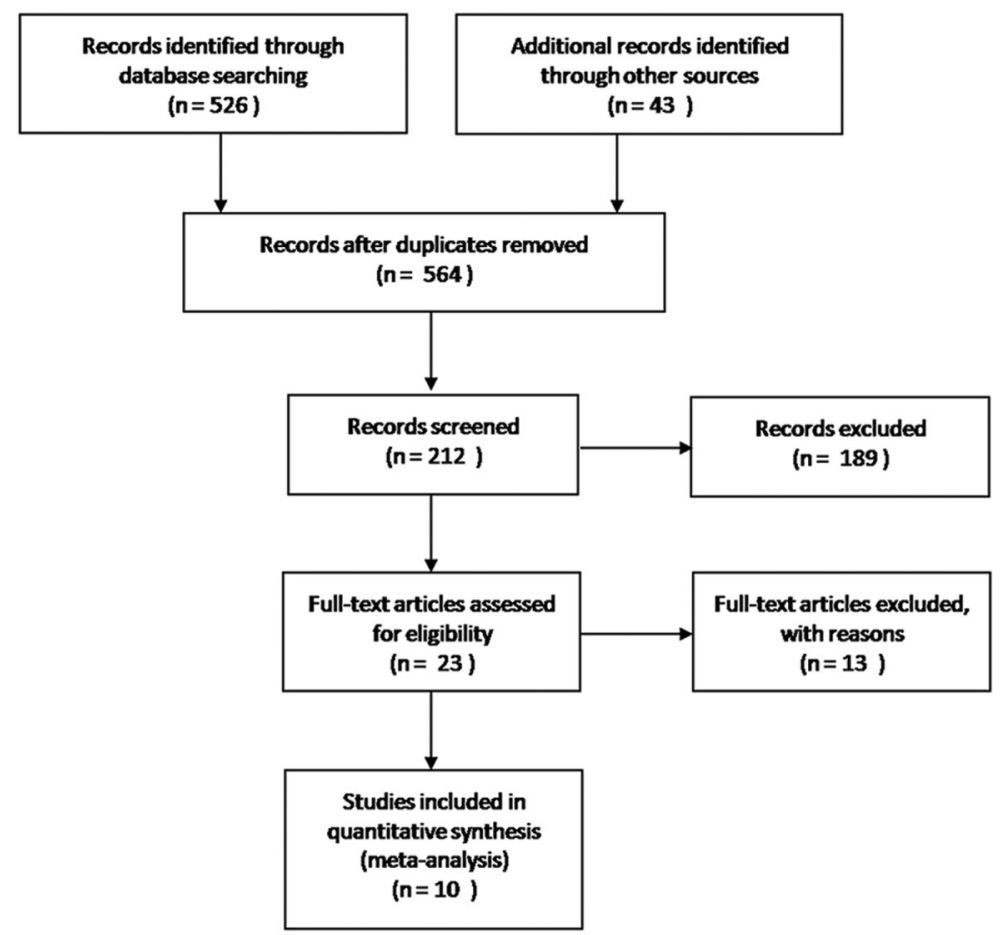

Figure 1. Identification of studies for inclusion in the meta-analysis.

System (version 9.0; SAS Institute, USA) and RevMan 5 software (Cochrane Information Management System) were used for all statistical analyses. All tests were two-sided, and statistical significance was defined as $\mathrm{P}<0.05$ unless otherwise stated.

\section{Results}

A total of 564 potentially relevant RCTs were initially retrieved. Of these, 352 articles were excluded as the titles were not relevant. An additional 189 trials were then excluded by abstract review. After the two reviewing authors had independently read the full texts, 23 more studies were excluded. Ultimately, 10 trials including 634 patients were deemed eligible for inclusion in this metaanalysis (Figure 1).

Table 1 shows the baseline characteristics of subjects included in all 10 RCTs $(17,18,27-34)$, including mean age, diagnostic criteria, HDRS or MARDS score, TRD definition, primary diagnosis, and TRD staging. Table 2 shows the quality assessment scores. Table 3 shows the rTMS treatment parameters of all 10 RCTs $(17,18,27-34)$, including stimulation placement, frequency, intensity, duration, total stimuli, and measurement outcomes. With regard to the other rTMS paradigms, 3 trials investigated unilateral rTMS, 4 evaluated sham rTMS, and 3 assessed both unilateral and sham rTMS.

Bilateral rTMS was not associated with significant improvements in primary or secondary outcomes compared with other rTMS paradigms, including unilateral and sham rTMS (Figure 2). The RRs were 1.50 (95\% Cl: 0.91-2.47) and 1.47 (95\% Cl: 0.56-3.82), respectively. There was statistically significant moderate heterogeneity among the 10 studies.

Subgroup analyses were conducted based on rTMS treatment paradigms. In the bilateral versus the unilateral rTMS analysis, bilateral rTMS was not associated with significant increases in response (Figure 3A) or remission (Figure 3B). The corresponding RR values were 1.01 (95\% $\mathrm{Cl}$ : $0.81-1.26)$ and 0.77 (95\% Cl: $0.52-1.16)$, with low to moderate heterogeneity among the studies. Furthermore, we performed subgroup analyses comparing the main parameters of bilateral and unilateral rTMS, including stimulation pattern, intensity, duration, and total stimuli. In the bilateral versus sham rTMS group, bilateral rTMS was significantly superior to sham rTMS with regard to the primary outcome (Figure $3 \mathrm{C}$ ), but there was no significant benefit for the secondary outcome (Figure 3D). The RR values were respectively $3.29(95 \% \mathrm{Cl}: 1.69-6.38)$ and 0.50 (95\% Cl: 0.19-1.31), with low heterogeneity.

Based on the modified Jadad scale scores, the present meta-analysis included 6 moderate- and 4 high-quality RCTs. Visual inspection of the inverted funnel plots of these RCTs showed them to be approximately symmetrical. Because the number of studies was too limited to show clear asymmetry, an Egger test was performed. The results showed that neither the primary outcome $(t=1.66, \mathrm{P}=$ $0.148)$ nor the secondary outcome $(t=1.37, \mathrm{P}=0.303)$ was influenced by publication bias. 
Table 1. Characteristics of patients in the included trials.

\begin{tabular}{|c|c|c|c|c|c|c|}
\hline Reference & $\begin{array}{c}\text { Mean age } \\
\text { (BG/OG, years) }\end{array}$ & $\begin{array}{l}\text { Diagnostic } \\
\text { criteria }\end{array}$ & $\begin{array}{l}\text { HDRS/MADRS } \\
\text { score }\end{array}$ & $\begin{array}{c}\text { TRD } \\
\text { definition }\end{array}$ & $\begin{array}{l}\text { Primary } \\
\text { diagnosis }\end{array}$ & $\begin{array}{l}\text { TRD } \\
\text { staging }\end{array}$ \\
\hline 17 & $\begin{array}{l}58.0 \pm 12.5 / \\
47.4 \pm 13.33\end{array}$ & DSM-IV & $17-\mathrm{HDRS}>21$ & $\begin{array}{l}\text { Failed } 2 \text { or more } \\
A D \text { at least } 6 \text { weeks }\end{array}$ & All with MDD & Stage II \\
\hline 27 & $\begin{array}{l}46.5 \pm 15.22 / \\
46.8 \pm 10.3\end{array}$ & ICD10 & $21-H D R S \geq 24$ & $\begin{array}{l}\text { Failed } 4 \mathrm{AD} \text { at } \\
\text { least } 6 \text { weeks }\end{array}$ & $\begin{array}{l}16.7 \% \text { with BD; } \\
83.3 \% \text { with MDD }\end{array}$ & Stage IV \\
\hline 30 & $\begin{array}{l}46.8 \pm 10.7 / \\
43.7 \pm 10.2\end{array}$ & DSM-IV & MADRS $>20$ & $\begin{array}{l}\text { Failed } 2 \text { or more } \\
A D \text { at least } 6 \text { weeks }\end{array}$ & $\begin{array}{l}16 \% \text { with BD; } \\
84 \% \text { with MDD }\end{array}$ & Stage II \\
\hline 34 & $\begin{array}{l}46.8 \pm 13.70 / \\
47.9 \pm 14.1\end{array}$ & MINI & 17-HDRS $>13$ & $\begin{array}{l}\text { Failed } 2 \text { or more } \\
A D \text { at least } 6 \text { weeks }\end{array}$ & $\begin{array}{l}15.1 \% \text { with BD; } \\
84.9 \% \text { with MDD }\end{array}$ & Stage II \\
\hline 18 & $\begin{array}{l}40.45 \pm 15.5 / \\
44.08 \pm 13.99\end{array}$ & $\mathrm{MINI}$ & $17-H D R S>15$ & $\begin{array}{l}\text { Failed } 2 \text { or more } \\
A D \text { at least } 6 \text { weeks }\end{array}$ & All with MDD & Stage II \\
\hline 31 & $\begin{array}{l}48.5 \pm 13.28 / \\
47.2 \pm 11.8\end{array}$ & DSM-IV & NA & $\begin{array}{l}\text { Failed } 2 \text { or more } \\
A D \text { at least } 4 \text { weeks }\end{array}$ & All with MDD & Stage II \\
\hline 28 & $\begin{array}{l}54.9 \pm 18.03 / \\
48.4 \pm 10.88\end{array}$ & DSM-IV & MADRS $\geq 25$ & Failed 1 or more $A D$ & $\begin{array}{l}15.8 \% \text { with BD; } \\
84.2 \% \text { with MDD }\end{array}$ & Stage I \\
\hline 32 & $49^{*} / 54^{*}$ & DSM-IV & $17-H D R S \geq 20$ & $\begin{array}{l}\text { Failed } 3 \text { or more } \\
A D \text { at least } 6 \text { weeks }\end{array}$ & $\begin{array}{l}12.9 \% \text { with } \mathrm{BD} ; \\
87.1 \% \text { with MDD }\end{array}$ & Stage III \\
\hline 33 & $\begin{array}{l}47.6 \pm 12.33 / \\
49.5 \pm 10.95\end{array}$ & DSM-IV & $17-H D R S \geq 18$ & $\begin{array}{l}\text { Failed } 2 \text { or more } \\
A D \text { at least } 6 \text { weeks }\end{array}$ & All with MDD & Stage II \\
\hline 29 & $\begin{array}{l}47.0 \pm 12.3 / \\
53.4 \pm 13.3\end{array}$ & DSM-IV & $17-H D R S \geq 18$ & $\begin{array}{l}\text { Failed } 1 \text { or more AD } \\
\text { in } 4 \text { or more weeks }\end{array}$ & $\begin{array}{l}16.7 \% \text { with } B D ; \\
83.3 \% \text { with MDD }\end{array}$ & Stage I \\
\hline
\end{tabular}

Data are reported as means \pm SD. rTMS: repetitive transcranial magnetic stimulation; BG: bilateral rTMS treatment group; OG: other rTMS paradigms group; HDRS: Hamilton Depression Rating Scale; MADRS: Montgomery and Åsberg Depression Rating Scale; TRD: treatment-resistant depression; DSM: Diagnostic and Statistical Manual of Mental Disorders; ICD: International Classification of Diseases; MINI: Mini-international Neuropsychiatric Interview; AD: antidepressant drug; BD: bipolar depression; MDD: major depressive disorder; NA: not available. *Median.

\section{Discussion}

The results of this meta-analysis demonstrate that the clinical efficacy of bilateral rTMS was not significantly greater than that of unilateral rTMS, but it was superior to sham rTMS in patients with TRD. Moreover, subgroup analyses revealed that the main parameters of bilateral rTMS, including stimulation pattern, intensity, duration, and total stimuli, did not significantly affect the lack of significance. It is disappointing that bilateral rTMS may not be a promising stimulation paradigm for treating TRD patients.

However, a previous systematic review regarding bilateral rTMS reached the opposite conclusion (19). The discrepancy between the two meta-analyses is likely due to the different numbers of included RCTs. The previous study included 7 RCTs involving 279 subjects, whereas we assessed 10 RCTs involving 634 subjects. Moreover, the

Table 2. Quality assessments of the included trials.

\begin{tabular}{lccccc}
\hline Reference & \multicolumn{5}{c}{ Literature quality } \\
\cline { 2 - 6 } & Randomization & Allocation & Blindness & Incomplete data & Total score \\
\hline 17 & 2 & 2 & 2 & 1 & 7 \\
27 & 1 & 0 & 2 & 1 & 4 \\
30 & 2 & 2 & 2 & 1 & 7 \\
34 & 2 & 0 & 2 & 1 & 5 \\
18 & 1 & 0 & 2 & 1 & 4 \\
31 & 1 & 2 & 2 & 1 & 6 \\
28 & 1 & 0 & 2 & 1 & 4 \\
32 & 1 & 0 & 2 & 1 & 4 \\
33 & 2 & 2 & 2 & 1 & 7 \\
29 & 1 & 0 & 2 & 1 & 4 \\
\hline
\end{tabular}

2: "yes"; 1: "unclear", 0: "no". 
Table 3. Design characteristics of the included trials.

\begin{tabular}{|c|c|c|c|c|c|c|c|}
\hline \multirow[t]{3}{*}{ Reference } & \multicolumn{5}{|c|}{ Parameters of rTMS } & \multicolumn{2}{|c|}{ Measurement outcomes } \\
\hline & \multicolumn{2}{|c|}{ Placement and frequency } & \multirow{2}{*}{$\begin{array}{l}\text { Intensity } \\
\text { (MT\%) }\end{array}$} & \multirow{2}{*}{$\begin{array}{l}\text { Duration } \\
\text { (weeks) }\end{array}$} & \multirow{2}{*}{$\begin{array}{l}\text { Total stimuli } \\
\quad \text { (pulse) }\end{array}$} & \multirow{2}{*}{$\begin{array}{l}\text { Response } \\
\text { (BG:OG) }\end{array}$} & \multirow{2}{*}{$\begin{array}{l}\text { Remission } \\
\text { (BG:OG) }\end{array}$} \\
\hline & BG & OG & & & & & \\
\hline \multirow[t]{2}{*}{17} & $\begin{array}{l}1 \mathrm{~Hz} \text { RPFC } \\
\text { followed by } \\
10 \mathrm{~Hz} \text { LPFC }\end{array}$ & 10 Hz LPFC; & $100-120$ & 6 & 36,450 & $10 / 28$ vs $1 / 24$ & $9 / 28$ vs $1 / 24$ \\
\hline & & $\begin{array}{l}\text { sham on unilateral } \\
\text { condition }\end{array}$ & & & & $10 / 28$ vs $2 / 22$ & $9 / 28$ vs $1 / 22$ \\
\hline \multirow[t]{2}{*}{27} & $\begin{array}{l}10 \mathrm{~Hz} \text { LPFC } \\
\text { alternated with } \\
1 \mathrm{~Hz} \text { RPFC }\end{array}$ & $\begin{array}{l}10 \mathrm{~Hz} \text { LPFC } \\
\text { alternated with } \\
1 \mathrm{~Hz} \text { LPFC; }\end{array}$ & 110 & 1 & 6,500 & $6 / 12$ vs $8 / 12$ & NA \\
\hline & & $10 \mathrm{~Hz}$ LPFC & & & & $6 / 12$ vs $10 / 12$ & \\
\hline 30 & $\begin{array}{l}1 \mathrm{~Hz} \text { RPFC } \\
\text { followed by } \\
10 \mathrm{~Hz} \text { LPFC }\end{array}$ & sham on both sides & $100-110$ & 2 & 11,700 & $11 / 25$ vs $2 / 25$ & $9 / 25$ vs $0 / 25$ \\
\hline \multirow[t]{2}{*}{34} & $\begin{array}{l}1 \mathrm{~Hz} \text { RPFC } \\
\text { followed by } \\
10 \mathrm{~Hz} \text { LPF; }\end{array}$ & $\begin{array}{l}1 \mathrm{~Hz} \text { RPFC followed } \\
\text { by } 10 \mathrm{~Hz} \text { sham RPFC }\end{array}$ & 110 & 4 & 36,000 & $40 / 71$ vs $39 / 71$ & $25 / 71$ vs $33 / 71$ \\
\hline & $\begin{array}{l}1 \mathrm{~Hz} \text { RPFC } \\
\text { followed by } \\
1 \mathrm{~Hz} \text { LPFC }\end{array}$ & & & & & $37 / 76$ vs $39 / 71$ & $22 / 76$ vs $33 / 71$ \\
\hline 18 & $\begin{array}{l}1 \mathrm{~Hz} \text { RPFC } \\
\text { followed by } \\
10 \mathrm{~Hz} \text { LPFC }\end{array}$ & $\begin{array}{l}1 \mathrm{~Hz} \text { sham RPFC } \\
\text { followed by } \\
10 \mathrm{~Hz} \text { LPFC; } \\
\text { sham on both sides }\end{array}$ & 120 & 3 & 36,000 & $1 / 22$ vs $0 / 20$ & NA \\
\hline 31 & $\begin{array}{l}1 \mathrm{~Hz} \text { RPFC } \\
\text { alternated with } \\
20 \mathrm{~Hz} \text { LPFC }\end{array}$ & sham on both sides & 110 & 2 & 30,000 & $2 / 10$ vs $0 / 10$ & NA \\
\hline 28 & $\begin{array}{l}15 \mathrm{~Hz} \\
\text { simultaneous } \\
\text { on both sides }\end{array}$ & sham on both sides & 90 & 3 & 54,000 & $2 / 9$ vs $1 / 10$ & NA \\
\hline \multirow[t]{2}{*}{32} & $\begin{array}{l}1 \mathrm{~Hz} \text { RPFC } \\
\text { followed by } \\
10 \mathrm{~Hz} \text { LPFC; }\end{array}$ & sham on both sides & 110 & 2 & 16,000 & $3 / 25$ vs $1 / 12$ & $0 / 25$ vs $0 / 12$ \\
\hline & $\begin{array}{l}10 \mathrm{~Hz} \text { LPFC } \\
\text { followed by } \\
1 \mathrm{~Hz} \text { RPFC }\end{array}$ & & & & & $7 / 25$ vs $1 / 12$ & $3 / 25$ vs $0 / 12$ \\
\hline \multirow[t]{2}{*}{33} & $\begin{array}{l}1 \mathrm{~Hz} \text { RPFC } \\
\text { followed by } \\
10 \mathrm{~Hz} \text { LPFC }\end{array}$ & $\begin{array}{l}1 \mathrm{~Hz} \text { RPFC } \\
\text { followed by } \\
10 \mathrm{~Hz} \text { sham LPFC; }\end{array}$ & 110 & 3 & 21,300 & $4 / 20$ vs $7 / 20$ & $2 / 20$ vs $6 / 20$ \\
\hline & & sham on both sides & & & & $4 / 20$ vs $2 / 20$ & $2 / 20$ vs $1 / 20$ \\
\hline 29 & $\begin{array}{l}20 \mathrm{~Hz} \text { LPFC } \\
\text { followed by } \\
1 \mathrm{~Hz} \text { RPFC }\end{array}$ & $\begin{array}{l}20 \mathrm{~Hz} \text { LPFC followed } \\
\text { by } 1 \mathrm{~Hz} \text { sham RPFC }\end{array}$ & 100 & 2 & 12,000 & $6 / 9$ vs $5 / 9$ & $4 / 9$ vs $5 / 9$ \\
\hline
\end{tabular}

rTMS: repetitive transcranial magnetic stimulation; BG: bilateral rTMS treatment group; OG: other rTMS paradigms group; MT: motor threshold; LPFC: left prefrontal cortex; RPFC: right prefrontal cortex; N: not available.

previous comparison of unilateral and bilateral rTMS was based on just 2 RCTs, compared to 6 in the current study. It is possible that our literature search strategy identified additional trials. In the previous meta-analysis, Berlim et al. (19) claimed that previous meta-analyses screened the database up to late 2008, and therefore only searched Medline from 1 October 2008 until 20 July 2012. Because the included trials from previous meta-analyses may not fully represent all of the published data, the analyses may have suffered from significant bias. In addition, the review by Berlim et al. (19) aimed to directly compare sham and bilateral rTMS in MDD patients; unilateral rTMS was not included in the discussion. However, in this review, we performed a subgroup analysis of bilateral and unilateral rTMS in TRD patients.

There was statistical heterogeneity for both response and remission in bilateral versus other rTMS paradigms. However, a subgroup analysis comparing unilateral and sham rTMS did not show significant heterogeneity with regard to response or remission. This heterogeneity may 


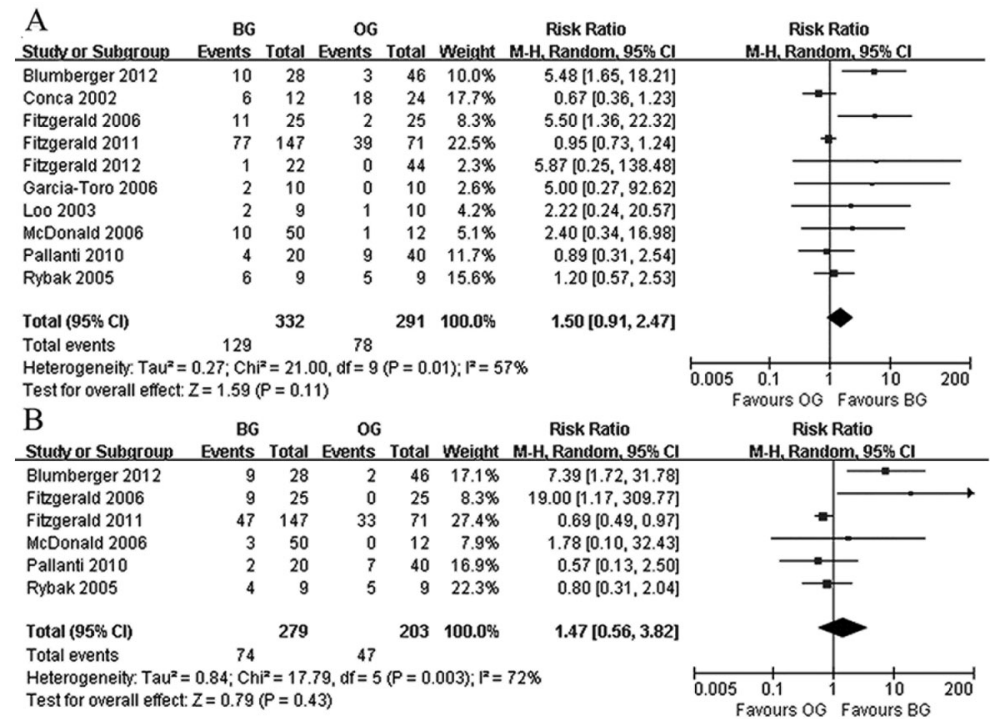

Figure 2. Primary outcome and secondary outcome: bilateral rTMS vs other rTMS paradigms. $A$, Comparison of bilateral rTMS vs other paradigms rTMS for primary outcome: response at end of treatment. $B$, Comparison of bilateral rTMS vs other paradigms rTMS for primary outcome: remission at end of treatment. rTMS: repetitive transcranial magnetic stimulation; BG: bilateral rTMS treatment group; OG: other rTMS paradigms group. be due to the gross inconsistency in efficacies between unilateral and sham rTMS in TRD patients. In addition, heterogeneity may derive from the studies' different diagnostic criteria, ages, and TRD stages, which were also reported by another systematic review on rTMS for TRD (35).

Our findings did not indicate that bilateral rTMS was superior to unilateral rTMS, but we did observe moderate heterogeneity. This heterogeneity was investigated by subgroup analyses of rTMS parameters, including stimulation pattern, intensity, duration, and total stimuli. Variations in these parameters could play important roles in rTMS treatment outcomes (36). Three bilateral rTMS stimulation patterns were reviewed in this study: simultaneous rTMS, low-frequency right PFC followed by high-frequency left PFC rTMS, and high-frequency left PFC rTMS followed by low-frequency right PFC. Moreover, some clinical studies

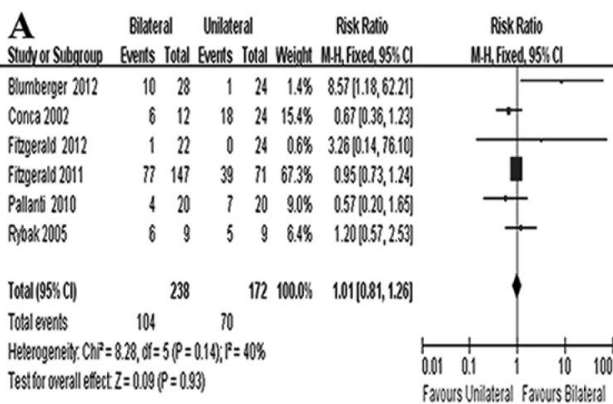

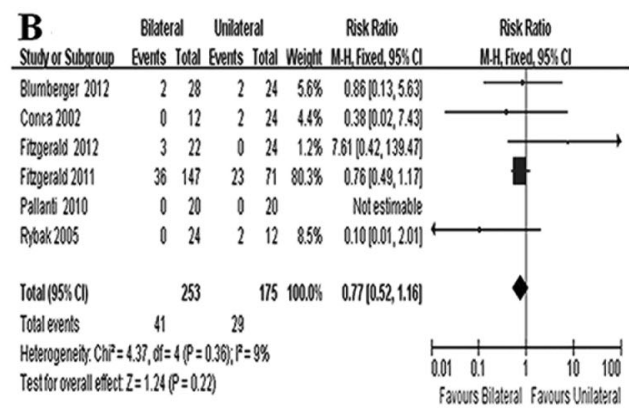

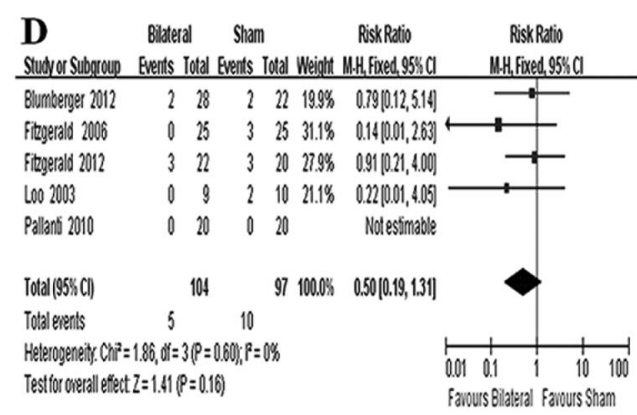

Figure 3. Subgroup analyses: bilateral vs unilateral repetitive transcranial magnetic stimulation (rTMS) and bilateral vs sham rTMS. A, Comparison of bilateral vs unilateral rTMS for primary outcome; $B$, comparison of bilateral vs unilateral rTMS for secondary outcome; $C$, comparison of bilateral vs sham rTMS for primary outcome; $D$, comparison of bilateral vs sham rTMS for secondary outcome. 
have classified stimulation intensities into $<110 \%$ motor threshold (MT), 110\% MT, and $>110 \%$ MT (37). Besides, the total treatment stimuli in the bilateral rTMS treatments were classified as $<36,000$ pulses or $\geq 36,000$ pulses. Thus, none of the bilateral rTMS parameter subgroups was associated with significant increases in response compared with unilateral rTMS. However, it is important to note that the subgroups included in these analyses only included data from a few RCTs.

There are two views regarding the use of bilateral and unilateral rTMS in patients with TRD. The first is based on the presence of a "nondominant hemisphere response pattern" in MDD patients compared to a "bilateral response pattern" in most healthy volunteers (38). In addition, some researchers have pointed out that right-handed patients may benefit more from left high-frequency rTMS, whereas left-handed patients may benefit more from right low-frequency rTMS $(32,33)$. Therefore, bilateral rTMS may only activate the dominant hemisphere in depressed patients, producing a unilateral antidepressant effect. The second view is that unilateral prefrontal rTMS produces bilateral effects in cases of high-intensity stimulation. Nahas et al. (39) reported that $80 \%$ MT only produces significant activation under the coil, $100 \%$ MT produces contralateral activation, and 120\% MT produces bilateral prefrontal activation. Thus, the mechanism(s) underlying the antidepressant effect of bilateral rTMS effect remain uncertain.

Approximately 30 systematic reviews and meta-analyses of rTMS for MDD and TRD have been published, and most were pooled from randomized, double-blinded, and sham-controlled trials. Berlim et al. recently reported a

\section{References}

1. Kupfer DJ, Frank E, Phillips ML. Major depressive disorder: new clinical, neurobiological, and treatment perspectives. Lancet 2012; 379: 1045-1055, doi: 10.1016/S0140-6736(11) 60602-8.

2. World Health Organization. The global burden of disease: 2004 Update. http://www.who.int/healthinfo/global_burden_ disease/GBD_report_2004update_full.pdf. Accessed March 8, 2013.

3. Bschor T. Therapy-resistant depression. Expert Rev Neurother 2010; 10: 77-86, doi: 10.1586/ern.09.137.

4. Al-Harbi KS. Treatment-resistant depression: therapeutic trends, challenges, and future directions. Patient Prefer Adherence 2012; 6: 369-388, doi: 10.2147/PPA.S29716.

5. Blier P, Keller MB, Pollack MH, Thase ME, Zajecka JM, Dunner DL. Preventing recurrent depression: long-term treatment for major depressive disorder. J Clin Psychiatry 2007; 68: e06, doi: 10.4088/JCP.0307e06.

6. Brunoni AR, Fregni F. Clinical trial design in non-invasive brain stimulation psychiatric research. Int J Methods Psychiatr Res 2011; 20: e19-e30, doi: 10.1002/mpr.338.

7. Kozel FA, George MS. Meta-analysis of left prefrontal repetitive transcranial magnetic stimulation (rTMS) to treat depression. J Psychiatr Pract 2002; 8: 270-275, doi: 10.1097/ series of meta-analyses on rTMS for MDD, including high-frequency rTMS versus sham (40), low-frequency rTMS versus sham (10), high-frequency rTMS augmentation versus antidepressant (41), high-frequency rTMS versus electroconvulsive therapy (42), and bilateral rTMS versus other rTMS (19). The growing number of metaanalyses reflects the wide use of rTMS for patients with MDD and TRD and the urgent need for clinicians to standardize the application of this brain stimulation technique.

Several limitations should be taken into account when interpreting the present results. Although we conducted a systematic search and collected all related trials, the limited number of included RCTs may mean that the findings are underpowered (43). The large variation of stimulation parameters in each RCT, including stimulation pattern, frequency, intensity, duration, and total stimuli, could have significantly affected the impact on TRD patients (44). Owing to the limited number of relevant RCTs, we could not perform additional analyses to investigate which paradigm of bilateral rTMS would be more beneficial. Additional studies are needed to identify effective paradigms and characteristics of patients likely to gain the greatest benefit from rTMS.

\section{Acknowledgments}

This research was supported by the National Basic Research Program of China (973 Program; \#2009CB 918300) and the Natural Science Foundation of China (NSFC, \#31271189).

\section{6-200209000-00003.}

8. Schutter DJ. Antidepressant efficacy of high-frequency transcranial magnetic stimulation over the left dorsolateral prefrontal cortex in double-blind sham-controlled designs: a meta-analysis. Psychol Med 2009; 39: 65-75, doi: 10.1017/ S0033291708003462.

9. Dell'osso B, Camuri G, Castellano F, Vecchi V, Benedetti M, Bortolussi S, et al. Meta-review of metanalytic studies with repetitive transcranial magnetic stimulation (rTMS) for the treatment of major depression. Clin Pract Epidemiol Ment Health 2011; 7: 167-177, doi: 10.2174/1745017901107010167.

10. Berlim MT, Van den Eynde F, Jeff Daskalakis Z. Clinically meaningful efficacy and acceptability of low-frequency repetitive transcranial magnetic stimulation (rTMS) for treating primary major depression: a meta-analysis of randomized, double-blind and sham-controlled trials. Neuropsychopharmacology 2013; 38: 543-551, doi: 10.1038/npp.2012.237.

11. Drevets WC. Orbitofrontal cortex function and structure in depression. Ann N Y Acad Sci 2007; 1121: 499-527, doi: 10.1196/annals.1401.029.

12. Grimm S, Beck J, Schuepbach D, Hell D, Boesiger $P$, Bermpohl F, et al. Imbalance between left and right dorsolateral prefrontal cortex in major depression is linked to 
negative emotional judgment: an fMRI study in severe major depressive disorder. Biol Psychiatry 2008; 63: 369-376, doi: 10.1016/j.biopsych.2007.05.033.

13. Speer AM, Benson BE, Kimbrell TK, Wassermann EM, Willis MW, Herscovitch $\mathrm{P}$, et al. Opposite effects of high and low frequency rTMS on mood in depressed patients: relationship to baseline cerebral activity on PET. J Affect Disord 2009; 115: 386-394, doi: 10.1016/j.jad.2008.10.006.

14. Speer AM, Kimbrell TA, Wassermann EM, Repella D, Willis MW, Herscovitch P, et al. Opposite effects of high and low frequency rTMS on regional brain activity in depressed patients. Biol Psychiatry 2000; 48: 1133-1141, doi: 10.1016/ S0006-3223(00)01065-9.

15. Fierro B, Brighina F, Vitello G, Piazza A, Scalia S, Giglia G, et al. Modulatory effects of low- and high-frequency repetitive transcranial magnetic stimulation on visual cortex of healthy subjects undergoing light deprivation. J Physiol 2005; 565: 659-665, doi: 10.1113/jphysiol.2004.080184.

16. Ebmeier KP, Donaghey C, Steele JD. Recent developments and current controversies in depression. Lancet 2006; 367: 153-167, doi: 10.1016/S0140-6736(06)67964-6.

17. Blumberger DM, Mulsant BH, Fitzgerald PB, Rajji TK, Ravindran AV, Young LT, et al. A randomized double-blind sham-controlled comparison of unilateral and bilateral repetitive transcranial magnetic stimulation for treatmentresistant major depression. World J Biol Psychiatry 2012; 13: 423-435, doi: 10.3109/15622975.2011.579163.

18. Fitzgerald PB, Hoy KE, Herring SE, McQueen S, Peachey AV, Segrave RA, et al. A double blind randomized trial of unilateral left and bilateral prefrontal cortex transcranial magnetic stimulation in treatment resistant major depression. J Affect Disord 2012; 139: 193-198, doi: 10.1016/j.jad.2012.02.017.

19. Berlim MT, Van den Eynde F, Daskalakis ZJ. A systematic review and meta-analysis on the efficacy and acceptability of bilateral repetitive transcranial magnetic stimulation (rTMS) for treating major depression. Psychol Med 2013; 43: 2245-2254, doi: 10.1017/S0033291712002802.

20. Zheng P, Wang Y, Chen L, Yang D, Meng H, Zhou D, et al. Identification and validation of urinary metabolite biomarkers for major depressive disorder. Mol Cell Proteomics 2013; 12: 207-214, doi: 10.1074/mcp.M112.021816.

21. Thase ME, Rush AJ. Treatment resistant depression. In: Bloom FE, Kupfer DJ (Editors), Psychopharmacology: The fourth generation of progress. New York: Raven Press Ltd.; 1995. p 1081-1097.

22. Hefner J, Ashton AK, D'Mello DA, Dantz B, Leon FG, Matson $\mathrm{GA}$, et al. Response to treatment: gaining and maintaining remission from depression. J Fam Pract 2003; Suppl: S61S62.

23. Riedel M, Moller HJ, Obermeier M, Schennach-Wolff R, Bauer $\mathrm{M}$, Adli $\mathrm{M}$, et al. Response and remission criteria in major depression - a validation of current practice. J Psychiatr Res 2010; 44: 1063-1068, doi: 10.1016/j.jpsychires.2010.03.006.

24. Cipriani A, Furukawa TA, Salanti G, Geddes JR, Higgins JP, Churchill R, et al. Comparative efficacy and acceptability of 12 new-generation antidepressants: a multiple-treatments metaanalysis. Lancet 2009; 373: 746-758, doi: 10.1016/S01406736(09)60046-5.

25. Higgins JP, Thompson SG, Deeks JJ, Altman DG. Measuring inconsistency in meta-analyses. BMJ 2003; 327: 557-560, doi: $10.1136 / \mathrm{bmj} .327 .7414 .557$.
26. Zhou X, Chen J, Li Q, Ren G, Yao G, Liu M, et al. Minimally invasive surgery for spontaneous supratentorial intracerebral hemorrhage: a meta-analysis of randomized controlled trials. Stroke 2012; 43: 2923-2930, doi: 10.1161/STROKEAHA.112. 667535

27. Conca A, Di Pauli J, Beraus W, Hausmann A, Peschina W, Schneider $\mathrm{H}$, et al. Combining high and low frequencies in rTMS antidepressive treatment: preliminary results. Hum Psychopharmacol 2002; 17: 353-356, doi: 10.1002/hup. 422.

28. Loo CK, Mitchell PB, Croker VM, Malhi GS, Wen W, Gandevia SC, et al. Double-blind controlled investigation of bilateral prefrontal transcranial magnetic stimulation for the treatment of resistant major depression. Psychol Med 2003; 33: $33-40$.

29. Rybak M, Bruno R, Turnier-Shea Y, Pridmore S. An attempt to increase the rate and magnitude of the antidepressant effect of transcranial magnetic stimulation (TMS). Ger J Psych 2005; 8: 59-65.

30. Fitzgerald PB, Benitez J, De Castella A, Daskalakis ZJ, Brown TL, Kulkarni J. A randomized, controlled trial of sequential bilateral repetitive transcranial magnetic stimulation for treatment-resistant depression. Am J Psychiatry 2006; 163: 88-94, doi: 10.1176/appi.ajp.163.1.88.

31. Garcia-Toro M, Salva J, Daumal J, Andres J, Romera M, Lafau $\mathrm{O}$, et al. High $(20-\mathrm{Hz})$ and low $(1-\mathrm{Hz})$ frequency transcranial magnetic stimulation as adjuvant treatment in medication-resistant depression. Psychiatry Res 2006; 146: 53-57, doi: 10.1016/j.pscychresns.2004.08.005.

32. McDonald WM, Easley K, Byrd EH, Holtzheimer P, Tuohy $\mathrm{S}$, Woodard $\mathrm{JL}$, et al. Combination rapid transcranial magnetic stimulation in treatment refractory depression. Neuropsychiatr Dis Treat 2006; 2: 85-94.

33. Pallanti S, Bernardi S, Di Rollo A, Antonini S, Quercioli L. Unilateral low frequency versus sequential bilateral repetitive transcranial magnetic stimulation: is simpler better for treatment of resistant depression? Neuroscience 2010; 167 : 323-328, doi: 10.1016/j.neuroscience.2010.01.063.

34. Fitzgerald PB, Hoy K, Gunewardene R, Slack C, Ibrahim S, Bailey $\mathrm{M}$, et al. A randomized trial of unilateral and bilateral prefrontal cortex transcranial magnetic stimulation in treatment-resistant major depression. Psychol Med 2011; 41: 1187-1196, doi: 10.1017/S0033291710001923.

35. Lam RW, Chan P, Wilkins-Ho M, Yatham LN. Repetitive transcranial magnetic stimulation for treatment-resistant depression: a systematic review and metaanalysis. Can $J$ Psychiatry 2008; 53: 621-631.

36. George MS. Transcranial magnetic stimulation for the treatment of depression. Expert Rev Neurother 2010; 10: 1761-1772, doi: 10.1586/ern.10.95.

37. Padberg F, Zwanzger P, Keck ME, Kathmann N, Mikhaiel P, Ella $R$, et al. Repetitive transcranial magnetic stimulation (rTMS) in major depression: relation between efficacy and stimulation intensity. Neuropsychopharmacology 2002; 27: 638-645, doi: 10.1016/S0893-133X(02)00355-X.

38. Okada F, Takahashi N, Tokumitsu Y. Dominance of the 'nondominant' hemisphere in depression. J Affect Disord 1996; 37: 13-21, doi: 10.1016/0165-0327(95)00040-2.

39. Nahas Z, Lomarev M, Roberts DR, Shastri A, Lorberbaum JP, Teneback C, et al. Unilateral left prefrontal transcranial magnetic stimulation (TMS) produces intensity-dependent 
bilateral effects as measured by interleaved BOLD fMRI. Biol Psychiatry 2001; 50: 712-720, doi: 10.1016/S0006-3223 (01)01199-4.

40. Berlim MT, Van den Eynde F, Tovar-Perdomo S, Daskalakis ZJ. Response, remission and drop-out rates following highfrequency repetitive transcranial magnetic stimulation (rTMS) for treating major depression: a systematic review and metaanalysis of randomized, double-blind and sham-controlled trials. Psychol Med 2014; 44: 225-239, doi: 10.1017/S003329 1713000512.

41. Berlim MT, Van den Eynde F, Daskalakis ZJ. Highfrequency repetitive transcranial magnetic stimulation accelerates and enhances the clinical response to antidepressants in major depression: a meta-analysis of randomized, double-blind, and sham-controlled trials. J Clin Psychiatry 2013; 74: e122-e129, doi: 10.4088/JCP.12r07996.

42. Berlim MT, Van den Eynde F, Daskalakis ZJ. Efficacy and acceptability of high frequency repetitive transcranial magnetic stimulation (rTMS) versus electroconvulsive therapy (ECT) for major depression: a systematic review and metaanalysis of randomized trials. Depress Anxiety 2013; 30: 614-623, doi: 10.1002/da.22060.

43. Silber S. A new and rapid scoring system to assess the scientific evidence from clinical trials. J Interv Cardiol 2006; 19: 485-492, doi: 10.1111/j.1540-8183.2006.00205.x.

44. Repetitive transcranial magnetic stimulation for the treatment of major depressive disorder: an evidence-based analysis. Ont Health Technol Assess Ser 2004; 4: 1-98. 